\title{
Retrospective analysis of the efficacy of percutaneous transhepatic biliary drainage in palliation of obstructive jaundice in patients with carcinoma gall bladder: Experience from tertiary care center in Northern India
}

\author{
Milind B. Sawant ${ }^{1}$, S. Harish ${ }^{2}$, Nishant Lohia ${ }^{3}$, S. Anand ${ }^{4}$, Manoj Prashar ${ }^{5}$, Sankalp Singh ${ }^{6}$, \\ Gaurav Trivedi ${ }^{7}$ \\ ${ }^{1}$ Assistant Professor, Department of Radiology, ${ }^{2}$ Professor, Department of Surgical Oncology, Command Hospital \\ (CC), Lucknow, Uttar Pradesh, ${ }^{3}$ Assistant Professor, Department of Radiation Oncology, Command Hospital Air Force, \\ Bangalore, Karnataka, ${ }^{4}$ Professor, Department of Surgical Oncology, Command Hospital (SC), Pune, ${ }^{5}$ Professor, \\ Department of Medical Oncology, Command Hospital (SC), Pune, ${ }^{6}$ Professor, ${ }^{7}$ Assistant Professor, Department of \\ Radiation Oncology, Command Hospital (CC), Lucknow, Uttar Pradesh, India
}

\section{A B S T R A C T}

Introduction: Percutaneous Transhepatic Biliary Drainage (PTBD) is a minimally invasive procedure to palliate the biliary obstruction caused by unresectable malignancy. Aim and Objectives: To analyze the outcome of PTBD in patients of unresectable gall bladder cancer presenting with obstructive jaundice in terms of reduction in serum bilirubin levels, symptomatic improvement, and overall survival (OS) at 4 weeks and 12 weeks following the procedure. Materials and Methods: In this retrospective study, PTBD was attempted on 30 patients diagnosed with inoperable gall bladder cancer. Various patient and procedurerelated variables were analyzed and recorded both pre and post-PTBD. Outcome data on OS was collected at 4 weeks and 12 weeks. Results: Technical success was achieved in $29(99.66 \%)$ patients. The mean fall in the serum bilirubin at the $7^{\text {th }}$ post-procedural day was $41.5 \%$ after the successful PTBD. The most common complication in our study was cholangitis noted in six (21\%) patients. OS at 4 weeks and 12 weeks was $79 \%$ and $41 \%$, respectively. Conclusion: Younger age and good performance status favored better survival rate in our study.

Key words: Gall bladder cancer; Malignant biliary obstruction; Overall survival;

Percutaneous transhepatic biliary drainage
Access this article online

\section{Website:}

http://nepjol.info/index.php/AJMS DOI: 10.3126/ajms.v12i11.38761 E-ISSN: 2091-0576 P-ISSN: $2467-9100$

Copyright (c) 2021 Asian Journal of Medical Sciences

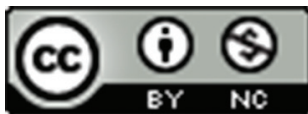

This work is licensed under a Creative Commons Attribution-NonCommercial 4.0 International License.

\section{INTRODUCTION}

Gall bladder cancer is an aggressive biliary tract malignancy that is one of the most common causes of malignant obstructive jaundice in northern India. ${ }^{1-3}$ Obstructed biliary system is a potentially dangerous condition which predisposes to cholangitis, septicemia, and hepatic dysfunction resulting in high mortality. Most of these patients who present with obstructive jaundice will have a disease that is surgically unresectable. ${ }^{4}$ Hence, palliative biliary drainage is the primary aim when curative resection is not possible due to either locally advanced disease or distant metastases. Biliary drainage is usually achieved by either endoscopic retrograde placement of stent or fluoroscopy-guided percutaneous transhepatic approach. The percutaneous transhepatic biliary drainage (PTBD) is usually done after a failed endoscopic biliary drainage as endoscopic procedure is relatively less invasive and 
associated with lower adverse events as compared to PTBD. ${ }^{5}$

\section{Aims and objectives}

The primary aim of the study was to analyze the outcome of biliary decompression by PTBD in patients with carcinoma gall bladder presenting with obstructive jaundice in terms of reduction in serum bilirubin levels and symptomatic improvement with secondary objectives of determining overall survival (OS) at 4 weeks and 12 weeks following the procedure.

\section{MATERIALS AND METHODS}

Total of 106 patients with gall bladder cancer were registered in our Malignant Disease Treatment Centre during the period from January 2019 to April 2020. Out of these 106 patients, 18 patients underwent curative surgery. The remaining 88 patients had either locally advanced unresectable or metastatic disease. Forty-six patients had obstructive jaundice at presentation, out of which 16 patients underwent successful endoscopic biliary drainage. The remaining 30 patients with failed endoscopic biliary drainage were taken up for PTBD. Pre-procedure serum bilirubin, symptoms, and performance status was analyzed. Performance status was assessed using the Eastern Cooperative Oncology group (ECOG) scale before the procedure. Pain abdomen was recorded on the Visual Analog Scale.

Out of these 30 patients, the technical success (hepatic duct cannulation and free flow of bile at the end of the procedure) was achieved in only 29 patients. Hence, one patient was excluded and only 29 patients were included in the final study analysis. All these patients underwent initial abdominal imaging studies with ultrasonography (USG) and contrast-enhanced computed tomography (CT) abdomen/Magnetic resonance cholangio-pancreatography prior to initiation of the therapeutic procedure. USG/CT guided fine-needle aspiration cytology/biopsy was done for diagnosis of malignant disease. Baseline hemogram, liver function tests (LFT), Prothrombin time, and International normalized ratio (INR) were recorded in all patients a day prior to the procedure. INR value of $<1.5$ was prerequisite for initiation of the procedure. Patients with coagulopathy and deranged INR were optimized by intravenous injection of Vitamin K $10 \mathrm{mg}$ daily for three doses and transfusion of fresh frozen plasma. Patients with significant ascites underwent preprocedural paracentesis. Patients were kept fasting for $6 \mathrm{~h}$ prior to intervention and given adequate intravenous fluids to keep them well-hydrated. A single dose of $3^{\text {rd }}$ generation cephalosporin intravenous antibiotic was administered 60 min prior to the procedure.

\section{Procedure}

PTBD procedures were performed in digital subtraction angiography suite by interventional radiologist who has experience of more than 100 PTBD procedures. All procedures were performed under strict aseptic precautions. Procedures were done using conscious sedation with shortacting benzodiazepines and narcotic agents.

Post-procedure, all patients were given intravenous antibiotics, adequate fluids, and analgesics. Evaluation of serum bilirubin was done on the $7^{\text {th }}$ post-procedure day. Relief of itching and abdominal pain and post-procedure complications were recorded.

The primary end-point was reduction in serum bilirubin, and relief of itching and abdominal pain. The secondary end-point was OS at 4 weeks and 12 weeks.

\section{Statistical analysis}

Various patient and procedure-related variables were analyzed and recorded both pre and post-PTBD as depicted in Tables 1 and 2. Outcome data on OS were collected at 4 weeks and 12 weeks (Table 3 ). OS was defined as time from date of PTBD procedure till death. Data were analyzed using crosstabs and Kaplan-Meier survival curves by Statistical Product and Service Solutions version 20 (SPSS 20, IBM, Armonk, NY, USA).

\begin{tabular}{|c|c|c|c|}
\hline $\begin{array}{l}\text { Study } \\
\text { parameters }\end{array}$ & Range & $\begin{array}{l}\text { Number of } \\
\text { Patients ( } n \text { ) }\end{array}$ & Percentage \\
\hline \multirow[t]{3}{*}{ Age in years } & $31-50$ & 8 & 28 \\
\hline & $51-70$ & 18 & 62 \\
\hline & $71-90$ & 3 & 10 \\
\hline \multirow[t]{2}{*}{ Gender } & Male & 6 & 21 \\
\hline & Female & 23 & 79 \\
\hline \multirow{4}{*}{ ECOG grades } & 0 & 1 & 3 \\
\hline & 1 & 14 & 48 \\
\hline & 2 & 12 & 41 \\
\hline & 3 & 2 & 7 \\
\hline Serum & $\leq 10$ & 3 & 10 \\
\hline \multirow[t]{3}{*}{ bilirubin range } & $>10-\leq 20$ & 13 & 45 \\
\hline & $>20-\leq 30$ & 9 & 31 \\
\hline & $>30$ & 4 & 14 \\
\hline Pain & Yes & 24 & 83 \\
\hline abdomen & No & 5 & 17 \\
\hline \multirow[t]{2}{*}{ Itching } & Yes & 23 & 79 \\
\hline & No & 6 & 21 \\
\hline \multirow{2}{*}{ Ascites } & Yes & 6 & 21 \\
\hline & No & 23 & 79 \\
\hline \multirow{3}{*}{ Bismuth types } & 1 & 8 & 28 \\
\hline & II & 13 & 44 \\
\hline & IIIA & 8 & 28 \\
\hline \multirow[t]{3}{*}{ PTBD } & Only right & 3 & 10 \\
\hline & Only left & 19 & 66 \\
\hline & $\begin{array}{l}\text { Both right } \\
\text { and left }\end{array}$ & 7 & 24 \\
\hline
\end{tabular}
biliary drainage 


\begin{tabular}{llcc} 
Table 2: Post PTBD data & Number of & Percentage \\
\hline Study parameters & Range & $\begin{array}{c}\text { Natients } \\
\text { (n) }\end{array}$ & \\
\hline Serum bilirubin & $\leq 10$ & 15 & 52 \\
range & $>10-\leq 20$ & 14 & 48 \\
Percentage & $1-20$ & 3 & 10 \\
decline in & $21-40$ & 8 & 28 \\
serum bilirubin & $41-60$ & 15 & 52 \\
post-PTBD & $>60$ & 3 & 10 \\
Catheter & Yes & 1 & 3 \\
Dislodgement & No & 28 & 97 \\
Pericatheter leak & Yes & 1 & 3 \\
Hemobilia & No & 28 & 97 \\
Yes & No & 27 & 7 \\
Cholangitis & Yes & 6 & 93 \\
Relief of pain & No & 23 & 21 \\
abdomen & Yes & 21 & 79 \\
Relief of itching & No & 8 & 72 \\
Yes & No & 10 & 28 \\
Internalized & Yes & 24 & 69 \\
Palliative & No & 5 & 31 \\
chemotherapy & Yes & 5 & 83 \\
\hline PTBD: Percutaneous transhepatic biliary drainage & 17 \\
& & 24 & 17 \\
& & & 83 \\
\hline
\end{tabular}

\begin{tabular}{|c|c|c|c|c|}
\hline Factors & $\begin{array}{c}\text { OS at } 4 \\
\text { weeks } \\
(\%)\end{array}$ & $\begin{array}{c}P \\
\text { value }\end{array}$ & $\begin{array}{c}\text { OS } \\
\text { at } 12 \\
\text { weeks } \\
(\%)\end{array}$ & $\begin{array}{c}P \\
\text { value }\end{array}$ \\
\hline \multicolumn{5}{|l|}{ Age in years } \\
\hline $31-50(n=8)$ & $87.5 \%$ & \multirow[t]{3}{*}{0.113} & $62.5 \%$ & \multirow[t]{3}{*}{0.046} \\
\hline $51-70(n=18)$ & $83.3 \%$ & & $38.9 \%$ & \\
\hline $71-90(n=3)$ & $33.3 \%$ & & $0.0 \%$ & \\
\hline \multicolumn{5}{|l|}{ Gender } \\
\hline Female $(n=17)$ & $73.9 \%$ & \multirow[t]{2}{*}{0.176} & $39.1 \%$ & \multirow[t]{2}{*}{0.479} \\
\hline Male $(n=6)$ & $100.0 \%$ & & $50.0 \%$ & \\
\hline \multicolumn{5}{|l|}{ ECOG grade } \\
\hline $0(n=1)$ & $100.0 \%$ & \multirow[t]{4}{*}{0.017} & $100.0 \%$ & \multirow[t]{4}{*}{0.011} \\
\hline $1(n=14)$ & $92.9 \%$ & & $50.0 \%$ & \\
\hline $2(n=12)$ & $75.0 \%$ & & $33.3 \%$ & \\
\hline $3(n=2)$ & $0.0 \%$ & & $0.0 \%$ & \\
\hline \multicolumn{5}{|l|}{$\begin{array}{l}\text { Decline in serum } \\
\text { bilirubin in } \%\end{array}$} \\
\hline $1-20(n=3)$ & $100.0 \%$ & \multirow[t]{4}{*}{0.457} & $66.7 \%$ & \multirow[t]{4}{*}{0.508} \\
\hline $21-40(n=8)$ & $62.5 \%$ & & $37.5 \%$ & \\
\hline $41-60(n=15)$ & $80.0 \%$ & & $33.3 \%$ & \\
\hline$>60(n=3)$ & $100 \%$ & & $66.7 \%$ & \\
\hline \multicolumn{5}{|l|}{ Bismuth types } \\
\hline I $(n=8)$ & $62.5 \%$ & \multirow[t]{3}{*}{0.188} & $37.5 \%$ & \multirow[t]{3}{*}{0.777} \\
\hline II $(n=13)$ & $76.9 \%$ & & $38.5 \%$ & \\
\hline IIIA $(n=8)$ & $100.0 \%$ & & $50.0 \%$ & \\
\hline \multicolumn{5}{|l|}{ Type of PTBD } \\
\hline Both right and & $85.7 \%$ & \multirow[t]{4}{*}{0.760} & $28.6 \%$ & \multirow[t]{4}{*}{0.443} \\
\hline left $(n=7)$ & & & & \\
\hline Only left $(n=19)$ & $78.9 \%$ & & $47.4 \%$ & \\
\hline Only right $(n=3)$ & $66.7 \%$ & & $33.3 \%$ & \\
\hline \multicolumn{5}{|l|}{ Palliative } \\
\hline \multicolumn{5}{|l|}{ Chemotherapy } \\
\hline Yes $(n=5)$ & $100 \%$ & \multirow[t]{2}{*}{0.228} & $60 \%$ & \multirow[t]{2}{*}{0.198} \\
\hline No $(n=24)$ & $75 \%$ & & $37.5 \%$ & \\
\hline
\end{tabular}

The effect of patient-related and other variables such as age, gender, Performance status as per ECOG, decline in Serum Bilirubin in \%, type of biliary obstruction as per Bismuth classification, type of PTBD (right, left, or bilateral) and use of palliative chemotherapy on OS was estimated using Pearson's Chi-square test. Univariate analysis of association of above factors with OS and plotting of survival curves was carried out for these 29 patients. Table 3; Figures 1 and 2 show the results of the statistical analysis.

\section{RESULTS}

In our study population, $23(79 \%)$ were women and six $(21 \%)$ were men. The age of patients ranged from 31 years to 89 years with a mean age of 59.8 years. Apart from obstructive jaundice in all the patients, $24(83 \%)$ patients were symptomatic with abdominal pain, $23(79 \%)$ had generalized pruritus. Six (21\%) patients presented with ascites. Majority of patients belonged to ECOG group I $14(48 \%)$ and II 12 (41\%). Pre-procedure serum bilirubin was $<10 \mathrm{mg} / \mathrm{dl}$ in three $(10 \%)$ of patients. It was $10-20 \mathrm{mg} / \mathrm{dl}$ in $13(45 \%)$ of patients. In nine $(31 \%)$ patients, serum bilirubin was $20-30 \mathrm{mg} / \mathrm{dl}$ and four (14\%) patients had serum bilirubin more than $30 \mathrm{mg} / \mathrm{dl}$. Twentyfour $(83 \%)$ patients underwent internalization after $48 \mathrm{~h}$ following external drainage as secondary procedure. Five $(17 \%)$ patients could not be internalized as the stricture could not be negotiated. Hence, they remained on external biliary drainage. In all $29(100 \%)$ patients, procedure was done on dilated intrahepatic biliary radicles. In our study group, eight $(28 \%)$ patients had Bismuth type I stricture. Thirteen $(45 \%)$ patients had type II strictures. Eight $(28 \%)$ patients had type IIIA block. Seven $(24.1 \%)$ patients underwent bilateral PTBD. Three $(10.3 \%)$ patients underwent right-sided drainage. Nineteen (65.5\%) underwent left-sided drainage. Post-procedure serum bilirubin at the $7^{\text {th }}$ day was $<10 \mathrm{mg} / \mathrm{dl}$ in $15(52 \%)$ patients. Fourteen (48\%) patients had serum bilirubin between 10 and $20 \mathrm{mg} / \mathrm{dl}$. Percentage decline in serum bilirubin was up to $20 \%$ at 7 days following the procedure in three (10\%) patients. Eight (28\%) patients had between $21 \%$ and $40 \%$, $15(52 \%)$ patients had $41-60 \%$ and three $(10 \%)$ had more than $60 \%$ decline in the percentage of serum bilirubin. The mean pre-procedure serum bilirubin was $17.8 \mathrm{mg} \%$ (range 8.3-32.6 $\mathrm{mg} \%$ ). Post-procedural mean serum bilirubin was $10.4 \mathrm{mg} \%$ (range $1.7-18.3 \mathrm{mg} \%$ ). The mean fall in the serum bilirubin at the $7^{\text {th }}$ post-procedural day was $41.5 \%$. Relief of symptoms that is pain abdomen and pruritus was seen in $21(72 \%)$ of patients. Five (17\%) patients could achieve normalization of liver function and were subjected to palliative chemotherapy. Post-procedure cholangitis was encountered in six (21\%) patients. Transient hemobilia was seen in two $(7 \%)$ patients which was resolved within $24 \mathrm{~h}$. 


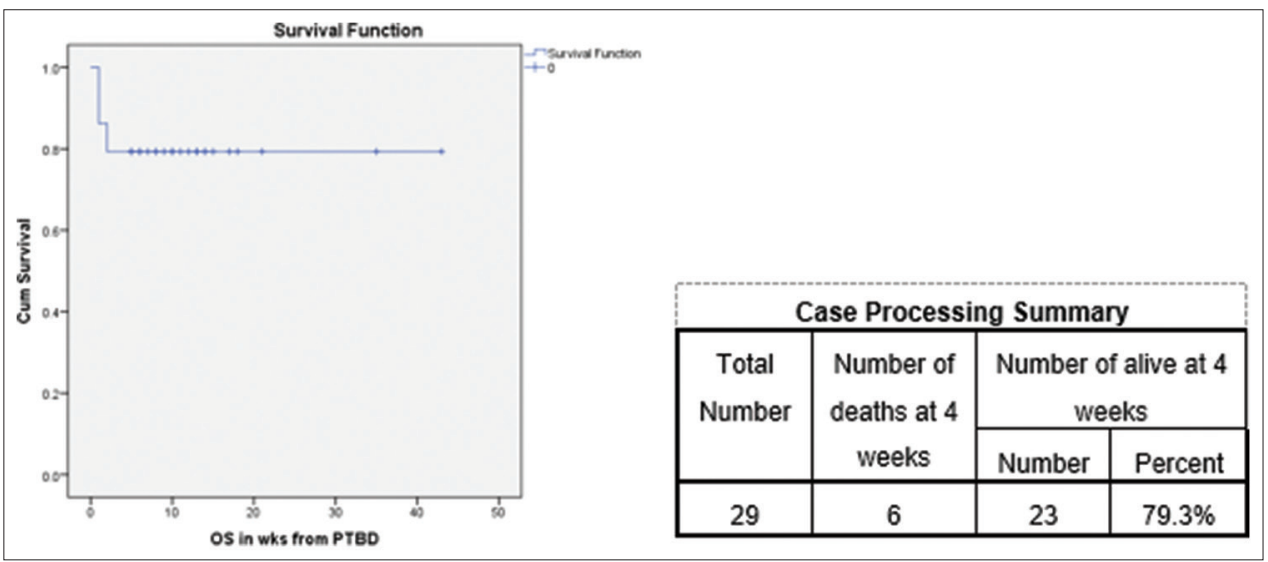

Figure 1: Overall survival at 4 weeks

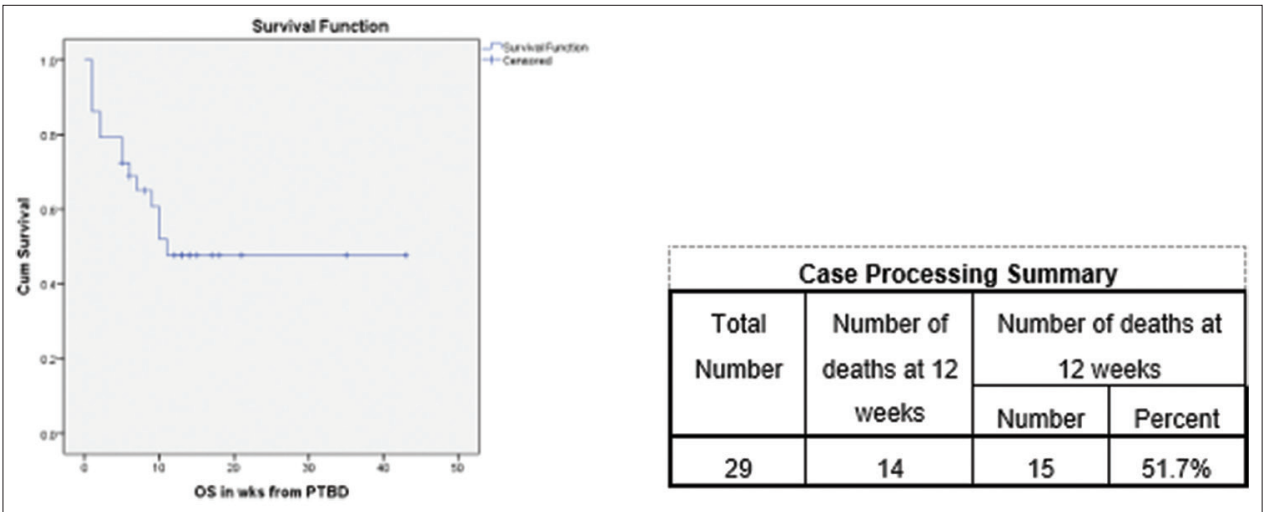

Figure 2: Overall survival at 12 weeks

Catheter dislodgement and pericatheter bile leak was seen in one patient each. No immediate post-procedure mortality was encountered. Five $(7 \%)$ patients died in $2^{\text {nd }}$ week following the procedure, out of which two patients died of cholangitis-related septicemic shock and three patients succumbed due to poor general condition as a result of advanced disease. Out of 29 patients, 23 (79\%) were alive at 4 weeks, $12(41 \%)$ were alive at 12 weeks following the procedure.

The OS at 4 weeks and 12 weeks following procedure is correlated significantly with age and performance status (ECOG score) with younger people and good performance status showing better survival as compared to elderly and patients with poorer performance status (Table 3). The OS is not significantly affected by other parameters such as gender, type of biliary block, type of biliary drainage (unilateral or bilateral), and use of palliative chemotherapy as depicted in Table 3. The better survival rates with statistical significance were seen in the younger patients and good performance status. About 100\% survival was seen at 4 weeks and $60 \%$ at 12 weeks in all five patients out of the 29 patients who received palliative chemotherapy. However, due to low number of patients (5 out of 29) receiving palliative chemotherapy, statistical significance was not achieved.

\section{DISCUSSION}

Malignant biliary obstructions (MBOs) commonly result from carcinoma head of the pancreas, cholangiocarcinoma, and carcinoma gall bladder. Other causes include hepatocellular carcinoma, lymphoma, and compression or infiltration by metastatic lymph nodes. The carcinoma gall bladder is the most common malignancy of the biliary tree in India, particularly in north and North-East states of Uttar Pradesh, Bihar, Orissa, West Bengal, and Assam with overall dismal prognosis. ${ }^{2,3}$ Several studies have described outcome of PTBD in MBOs. ${ }^{6-11}$ However, data with reference to the PTBD in inoperable carcinoma gall bladder is lacking. In this study, we have analyzed the outcome of PTBD in this subset of patients only.

Technical success was achieved in 29 patients out of total 30 patients $(99.66 \%)$. Robson et al., had a technical success rate of $100 \%$ in their study involving 109 patients with MBO. ${ }^{7}$ Knap et al., reported technical success in $90.7 \%$ in their study involving 168 patients. ${ }^{11}$ 
Post-procedure reduction in serum bilirubin was noted. The mean fall in the serum bilirubin at the $7^{\text {th }}$ post-procedural day was $41.5 \%$ after the successful PTBD. Knap et al., reported the average serum bilirubin before the procedure $23.22 \mathrm{mg} \%$ while post-procedure $17.42 \mathrm{mg} \%{ }^{0}{ }^{11}$ They also reported fall in serum alkaline phosphatase and gammaglutamyl transpeptidase. Five (17\%) patients were subjected to palliative chemotherapy following normalization of LFT.

The most common procedural complication in our study was cholangitis seen in six (21\%) patients. Various other studies also have reported cholangitis as the main complication. Teixeira et al., in their study of 71 patients with $\mathrm{MBO}$ reported cholangitis in $66.2 \%$ of cases. ${ }^{10} \mathrm{Xu}$ et al., reported incidence of new biliary infection after internal-external biliary drainage reached $47.6 \%$ in their study of 42 patients with $\mathrm{MBO} .{ }^{12}$ Sut et al., in their study of 21 patients with $\mathrm{MBO}$ had had cholangitis in 19\% patients after PTBD. ${ }^{8}$ There was no major bleeding complication in our study, though transient hemobilia was noted in two patients. The reported incidence of significant bleeding is $2-2.5 \%$ in most large case series. ${ }^{13,14}$

In this cohort, OS at 4 weeks and 12 weeks was $79 \%$ and $41 \%$, respectively. Tuqan et al., in their study of 72 patients of $\mathrm{MBO}$ who underwent percutaneous biliary drainage observed survival rates of $64 \%$ and $27 \%$ at 1 month and 3 months, respectively. ${ }^{15}$ Rees et al., in their study population of 16822 patients with unresectable MBO reported 7-day and 30-day mortality of $5.2 \%$ and $23.1 \%$, respectively, with a median survival of 92 days. ${ }^{16}$ The factors favoring survival with statistically significance in our study were younger age and good performance status. Many studies have reported better median survival rate in patients undergoing palliative chemotherapy following successful percutaneous biliary drainage. ${ }^{17-19}$ Kasuga et al., in their study observed that poor performance status, multiple liver metastases, presence of ascites, and not receiving palliative chemotherapy are poor prognostic factors after PTBD. ${ }^{18}$

The main strength of our retrospective study is that all PTBD procedures were done by the same interventional radiologist. Hence, there is no inter-operator difference in terms of technical skill or outcome measured. Another aspect of the study is that it is done in patients with $\mathrm{MBO}$ caused by gall bladder cancer only. However, the major limitation of the study is a small sample size which calls for prospective multicenter study involving large number of patients.

\section{CONCLUSION}

PTBD is an important and effective procedure for biliary tract decompression for palliation of obstructive jaundice in cases of surgically incurable carcinoma of gall bladder who have failed endoscopic biliary drainage. The procedure can help in symptomatic relief, improvement of general condition, and normalization of LFT which is prerequisite for initiation of palliative chemotherapy in majority of patients. Younger patients with good performance status had better OS. Patients who received palliative chemotherapy were noticed to have better OS in our study. However, large sample size is required to arrive at a statistically significant outcome.

\section{ACKNOWLEDGMENT}

Nil.

\section{REFERENCES}

1. Dutta U, Bush N, Kalsi D, Popli P and Kapoor VK. Epidemiology of gallbladder cancer in India. Chin Clin Oncol. 2019;8(4):33. https://doi.org/10.21037/cco.2019.08.03

2. Nandakumar A, Gupta PC, Gangadharan P, Visweswara RN and Parkin DM. Geographic pathology revisited: Development of an atlas of cancer in India. Int J Cancer. 2005;116(5):740-754. http://dx.doi.org/10.1002/ijc.21109

3. National Cancer Registry Programme. Two-year report of the Population Based Cancer Registries. New Delhi: Indian Council of Medical Research 2002. p. 1997-1998.

4. Miller $G$ and Jarnagin WR. Gallbladder carcinoma. Eur J Surg Oncol. 2008;34(3):306-312.

https://doi.org/10.1016/j.ejso.2007.07.206

5. Inamdar S, Slattery E, Bhalla R, Sejpal DV and Trindade AJ. Comparison of adverse events for endoscopic vs percutaneous biliary drainage in the treatment of malignant biliary tract obstruction in an inpatient national cohort. JAMA Oncol. 2016;2(1):112-117.

https://doi.org/10.1001/jamaoncol.2015.3670

6. Ferrucci JT Jr., Mueller PR and Harbin WP. Percutaneous transhepatic biliary drainage: Technique, results, and applications. Radiology. 1980;135(1):1-13.

https://doi.org/10.1148/radiology.135.1.7360943

7. Robson PC, Heffernan N, Gonen M, Thornton R, Brody LA, Holmes R, et al. Prospective study of outcomes after percutaneous biliary drainage for malignant biliary obstruction. Ann Surg Oncol. 2010;17(9):2303-2311.

https://doi.org/10.1245/s10434-010-1045-9

8. Sut M, Kennedy R, McNamee J, Collins A and Clements B. Longterm results of percutaneous transhepatic cholangiographic drainage for palliation of malignant biliary obstruction. J Palliat Med. 2010;13(11):1311-1313.

https://doi.org/10.1089/jpm.2010.0205

9. Iruarrizaga E, Azkona E, Martinez M, Iza E, Lopez-Vivanco G, Llarena AM, et al. Percutaneous transhepatic biliary drainage (PTBD) and endoscopic retrograde cholangiopancreatography (ERCP) for malignant obstructive jaundice (OJ) in advanced digestive cancers. J Clin Oncol. 2011;29(Suppl 4):abstr 348.

10. Teixeira MC, Mak MP, Marques DF, Capareli F, Carnevale FC, Moreira AM, et al. Percutaneous transhepatic biliary drainage in patients with advanced solid malignancies: Prognostic factors and clinical outcomes. J Gastrointest Cancer. 2013;44(4):398-403. 
https://doi.org/10.1007/s12029-013-9509-3

11. Knap D, Orlecka N, Judka R, Juza A, Drabek M, Honkowicz M, et al. Biliary duct obstruction treatment with aid of percutaneous transhepatic biliary drainage. Alexandria J Med. 2016;52(2):185-191. https://doi.org/10.1016/j.ajme.2015.07.003

12. Xu C, Lv PH, Huang XE, Sun L, Wang SX and Wang FA. Internalexternal percutaneous transhepatic biliary drainage for patients with malignant obstructive jaundice. Asian Pac J Cancer Prev. 2014;15(21):9391-9394.

https://doi.org/10.7314/apjcp.2014.15.21.9391

13. Fidelman N, Bloom Al, Kerlan RK Jr., Laberge JM, Wilson MW, Ring EJ, et al. Hepatic arterial injuries after percutaneous biliary interventions in the era of laparoscopic surgery and liver transplantation: Experience with 930 patients. Radiology. 2008;247(3):880-886.

https://doi.org/10.1148/radiol.2473070529

14. Aung TH, Too CW, Kumar N, Damodharan K, Urlings TA, Patel A, et al. Severe bleeding after percutaneous transhepatic drainage of the biliary system. Radiology. 2016;278(3):957-958.

https://doi.org/10.1148/radiol.2016151954

15. Tuqan W, Innabi A, Alawneh A, Farsakh FA and Al-Khatib M. Prediction of survival following percutaneous biliary drainage for malignant biliary obstruction. J TransI Intern Med. 2017;5(2):
127-131.

https://doi.org/10.1515/jtim-2017-0014

16. Rees J, Mytton J, Evison F, Mangat KS, Patel P and Trudgill N. The outcomes of biliary drainage by percutaneous transhepatic cholangiography for the palliation of malignant biliary obstruction in England between 2001 and 2014: A retrospective cohort study. BMJ Open. 2020;10(1):e033576.

http://dx.doi.org/10.1136/bmjopen-2019-033576

17. Van Laethem JL, De Broux S, Eisendrath P, Cremer M, Le Moine $\mathrm{O}$ and Devière $\mathrm{J}$. Clinical impact of biliary drainage and jaundice resolution in patients with obstructive metastases at the hilum. Am J Gastroenterol. 2003;98(6):1271-1277.

https://doi.org/10.1111/j.1572-0241.2003.07504.x

18. Kasuga A, Ishii H, Ozaka M, Matsusaka S, Chin K, Mizunuma N, et al. Clinical outcome of biliary drainage for obstructive jaundice caused by colorectal and gastric cancers. Jpn J Clin Oncol. 2012;42(12):1161-1167. https://doi.org/10.1093/jjco/hys168

19. Zhang GY, Li WT, Peng WJ, Li GD, He XH and Xu LC. Clinical outcomes and prediction of survival following percutaneous biliary drainage for malignant obstructive jaundice. Oncol Lett. 2014;7(4):1185-1190.

https://doi.org/10.3892/ol.2014.1860

\section{Authors Contribution:}

MBS - Concept and design of the study, carried out literature search of the study and prepared first draft of manuscript; HM - Helped in concept and design of the study and reviewed the manuscript; NL - Helped in making concept and design of study along with data and statistical analysis and did manuscript review; SA - literature search and manuscript preparation; MP - helped in design of study and in data and statistical analysis along with manuscript editing and review; SS - manuscript preparation and editing; GT - literature search and data analysis.

\section{Work attributed to:}

Department of Interventional Radiology, Command Hospital, Lucknow. (2) Department of Oncology, Command Hospital, Lucknow.

\section{Orcid ID:}

Dr. Milind B. Sawant - (iD https://orcid.org/0000-0001-6424-4520

Dr. S. Harish - (1) https://orcid.org/0000-0003-2331-6879

Dr. Nishant Lohia - (1) https://orcid.org/0000-0001-8767-9922

Dr. S. Anand - io https://orcid.org/0000-0002-9818-8624

Dr. Manoj Prashar - (D) https://orcid.org/0000-0002-4780-7026

Dr. Sankalp Singh - (D) https://orcid.org/0000-0001-8786-5258

Dr. Gaurav Trivedi - (iD https://orcid.org/0000-0002-7855-9045

Source of Support: Nil, Conflicts of Interest: None declared. 